\title{
Enterococcal meningitis in an HIV positive haemophilic patient
}

W N Patton, N Bienz, I M Franklin, J G M Hastings

\begin{abstract}
A 25 year old, human immunodeficiency virus (HIV) seropositive, severe haemophilic patient was treated for suspected Pneumocystis carinii infection with high dose intravenous cotrimoxazole and subsequently with prednisolone. When he improved he was discharged on oral treatment only to return two days later, extremely unwell, with headaches, fever, sweats, tachycardia and hypotension. A lumbar puncture showed modest neutrophil pleocytosis but despite empirical antibiotic treatment with intravenous benzylpenicillin and cefuroxime he continued to deteriorate. Culture of cerebrospinal fluid subsequently grew Enterococcus faecalis that was resistant to trimethoprim and sensitive to ampicillin, rifampicin, and vancomycin. After a change in treatment to intravenous ampicillin and rifampicin he dramatically improved.

Enterococcal meningitis is rare in adults but important to recognise and treat appropriately in view of its high mortality and relative resistance to antibiotics. In our case the combination of HIV infection and previous treatment with antibiotics or steroids, or both, were probable predisposing factors.
\end{abstract}

Enterococcal meningitis is rare but important to recognise and treat appropriately in view of its high mortality ${ }^{1}$ and relative resistance to antibiotics. $^{2}$ We report a case in a patient infected with human immunodeficiency virus (HIV), an association not previously recorded.

A 25 year old man with severe haemophilia was reported as HIV positive in 1985 . He remained asymptomatic until August 1990 when he presented with a two week history of a non-productive cough with mild tachycardia and fever that had not responded to one week's treatment with amoxycillin/clavulanic acid. His chest $x$-ray picture was normal, but he was treated intravenously with high dose cotrimoxazole (trimethoprim $20 \mathrm{mg} / \mathrm{kg} /$ day) and, after four days, with prednisolone $60 \mathrm{mg} /$ day for possible Pneumocystis carinii infection. He developed oral thrush which responded to topical nystatin and he was discharged seven days after admission on the above medication, but for oral consumption.

He presented again two days later, extremely unwell with frontal headache and sweats. Examination showed that he had a fever of $39 \cdot 2^{\circ} \mathrm{C}$, tachycardia of $130 /$ minute, and blood pressure of $85 / 50 \mathrm{mmHg}$, but no other abnormal signs. Lumbar puncture, performed under factor VIII cover, showed clear cerebrospinal fluid under normal pressure with $10 \times 10^{6} / 1$ polymorphs, no red cells, and no organisms on the Gram stain. Blood and urine cultures were sterile, the chest $x$-ray picture remained normal and an echocardiogram showed no evidence of endocarditis.

$\mathrm{He}$ was treated initially with intravenous benzylpenicillin $1.2 \mathrm{~g}$ four times a day, cefuroxime $750 \mathrm{mg}$ three times a day, and intravenous colloid, but he deteriorated with a fever of $41^{\circ} \mathrm{C}$. Culture of cerebrospinal fluid subsequently yielded Enterococcus faecalis that was sensitive to ampicillin, rifampicin, and vancomycin, but resistant to trimethoprim, chloramphenicol, and ciprofloxacin, and his treatment was changed to intravenous ampicillin $2 \mathrm{~g}$ four times a day and rifampicin $600 \mathrm{mg}$ daily. He improved rapidly with resolution of fever and tachycardia and considerable improvement of his headache within a further 36 hours.

Enterococci are a normal inhabitant of the gut flora. Enterococcal meningitis is well recognised in neonates, ${ }^{3}$ but in adults it is rare. It has been reported after endocarditis and in ill patients with bacteraemia and urinary tract infection. Other predisposing factors include neurosurgical procedures, central nervous system defects such as spina bifida, and previous prolonged antibiotic treatment. A common finding has been a low neutrophil response in the cerebrospinal fluid. The pathogenesis in our case remains unclear, although there were a number of predisposing factorsinfection with HIV, recent steroid treatment, and a possible preceding viral infection. The course of cotrimoxazole may have been responsible for the selection of a trimethoprim resistant enterococcus in the patient's gut flora. Enterococcal infection is not a well recognised complication of HIV disease and our patient had been previously asymptomatic with a normal T4 lymphocyte count of $0.7 \times 10^{9} / 1$

Previous authors have emphasised predisposing factors for enterococcal meningitis, the importance of its recognition, and the need to select appropriate antibiotics in the right dose with the right route of administration. We would add that the combination of HIV infection and previous treatment with antibiotics or steroids can predispose to this rare but serious infection. The absence of classic signs of meningism and poor response to initial empirical antibiotic treatment in our patient 
argues strongly for a low threshold for diagnostic lumbar puncture in such cases.

1 Bayer AS, Seidel JS, Yoshikawa TT, Anthony BF, Guze LB. Group D Enterococcal meningitis: Clinical and therapeutic considerations with report of three cases and review of the literature. Arch Intern Med 1976;136: review
2 Musher DM. Enterococcus species and group D streptococci. In Mandell GL, Douglas-RG, Bennett JE, eds. Principles and Practice of infectious diseases. New York: Churchill Livingstone, 1990:1550-4.

3 Klein JO, Marcy SM. Bacterial sepsis and meningitis. In: Remington JS, Klein JD, eds. Infectious diseases of the fetus and new born infant. Philadelphia: WB Saunders, 1983:679-734.

\title{
Haemorrhagic colitis and haemolytic-uraemic syndrome: False positive reaction with a rotavirus latex agglutination test
}

\author{
R P Bendall, J J Gray
}

\begin{abstract}
A stool sample from a child with haemorrhagic colitis and haemolyticuraemic syndrome gave a positive reaction with the RotaScreen latex agglutination test in the absence of other evidence of rotavirus infection. When this test is performed on bloody specimens, positive reactions should be interpreted with caution and confirmed by other means.
\end{abstract}

Haemorrhagic colitis can be caused by an infection with verotoxin producing strains of Escherichia coli $0157 .{ }^{1}$ This in turn has been associated with the haemolytic-uraemic syndrome $^{2}$ which is an uncommon condition, principally of children, and associated with significant morbidity and mortality. ${ }^{3}$ By contrast, rotavirus infection is a common, selflimiting condition and does not usually cause any long term sequelae. ${ }^{4}$ We describe a patient with haemorrhagic colitis and haemolyticuraemic syndrome whose stool gave a false positive reaction in a latex agglutination test for detecting rotavirus.

A 4 year old girl was admitted to this hospital with a three day history of diarrhoea, becoming bloody on the day of admission. She was vomiting but not clinically dehydrated.

Results of rotavirus antigen detection and electron microscopy

\begin{tabular}{|c|c|c|c|c|}
\hline \multirow{2}{*}{$\begin{array}{l}\text { Day faecal } \\
\text { sample taken }\end{array}$} & \multicolumn{2}{|c|}{ Latex agglutination } & \multirow{2}{*}{$\begin{array}{l}\text { Rotavirus antigen } \\
\text { ELISA }\end{array}$} & \multirow{2}{*}{$\begin{array}{l}\text { Electron } \\
\text { microscopy }\end{array}$} \\
\hline & Test & Control & & \\
\hline $\begin{array}{l}1 \\
3 \\
5\end{array}$ & $\begin{array}{l}++ \\
+ \\
-\end{array}$ & $\begin{array}{l}- \\
- \\
-\end{array}$ & $\begin{array}{l}\text { Negative } \\
\text { Negative } \\
\text { Negative }\end{array}$ & $\begin{array}{l}\text { No virus seen } \\
\text { No virus seen } \\
\text { No virus seen }\end{array}$ \\
\hline
\end{tabular}

She had an oral temperature of $37 \cdot 3^{\circ} \mathrm{C}$. Physical examination was normal and her white cell count was raised at $18.5 \times 10^{9} / 1$ with normal haemaglobin at $145 \mathrm{~g} / \mathrm{l}$ and a platelet count of $404 \times 10^{9} / 1$. Urea and electrolytes were all within normal limits (sodium $136 \mathrm{mmol} / \mathrm{l}$, potassium $4.0 \mathrm{mmol} / 1$, urea $3.2 \mathrm{mmol} / 1$ and creatinine $62 \mu \mathrm{mol} / \mathrm{l})$.

A faecal sample was sent for bacteriological and virological examination; it was bloody and liquid. The RotaScreen latex agglutination test (Mercia Diagnostics Ltd, Surrey) for detecting rotavirus antigen was performed according to the manufacturer's instructions on a centrifuged extract of this sample. It agglutinated the latex particles coated with rabbit anti-rotavirus antibody (test latex), but not the latex particles coated with normal rabbit globulin (control latex); this was interpreted as evidence of rotavirus infection.

By the third day after admission the patient had become oliguric with peripheral oedema noted on examination. The haemaglobin had fallen to $101 \mathrm{~g} / \mathrm{l}$, there was thrombocytopenia (platelet count of $54 \times 10^{9} / 1$ ) and a white cell count of $11.6 \times 10^{9} / 1$. The blood film contained numerous red cell fragments, spherocytes and burr cells. There was evidence of renal impairment with urea at $15 \mathrm{mmol} / 1$ and creatinine at $279 \mu \mathrm{mol} / 1$. Haemorrhagic colitis and haemolytic-uraemic syndrome were diagnosed.

The next day an organism, subsequently identified as a verotoxin producing strain of $E$ coli serotype 0157 , was isolated from the stool. No other enteric pathogens were isolated. Her renal function deteriorated further and she required peritoneal dialysis for 12 days.

Stool samples from days 1, 3, and 5 were retested with the RotaScreen test, examined by electron microscopy, and tested with a 